\section{Science meets forensic science}

\section{Washington}

THE photograph below, an example of evidence from the continuing misconduct investigation of Tufts University immunologist Thereza Imanishi-Kari, shows what the detective techniques of forensic science can do to analyse laboratory research records.

Faced with the problem of dating Imanishi-Kari's records to determine if fabrication occurred in the preparation of a 1987 Cell paper (see Nature $347,317 ; 1990)$, the staff of the congressional investigatory subcommittee of Representative John Dingell (Democrat, Michigan) focused on a series of gamma-counter tapes in the notebooks. They noted that the print quality of the tapes declined markedly as the machine's ribbon got older. On some of the tapes the staff also found a cumulative number stamp.

Joined by the Secret Service, the subcommittee staff decided to compare these tapes with tapes from notebooks of other researchers in the Massachusetts Institute of Technology laboratory where Imanishi-Kari had worked.

In Boston, they found that several other resear-

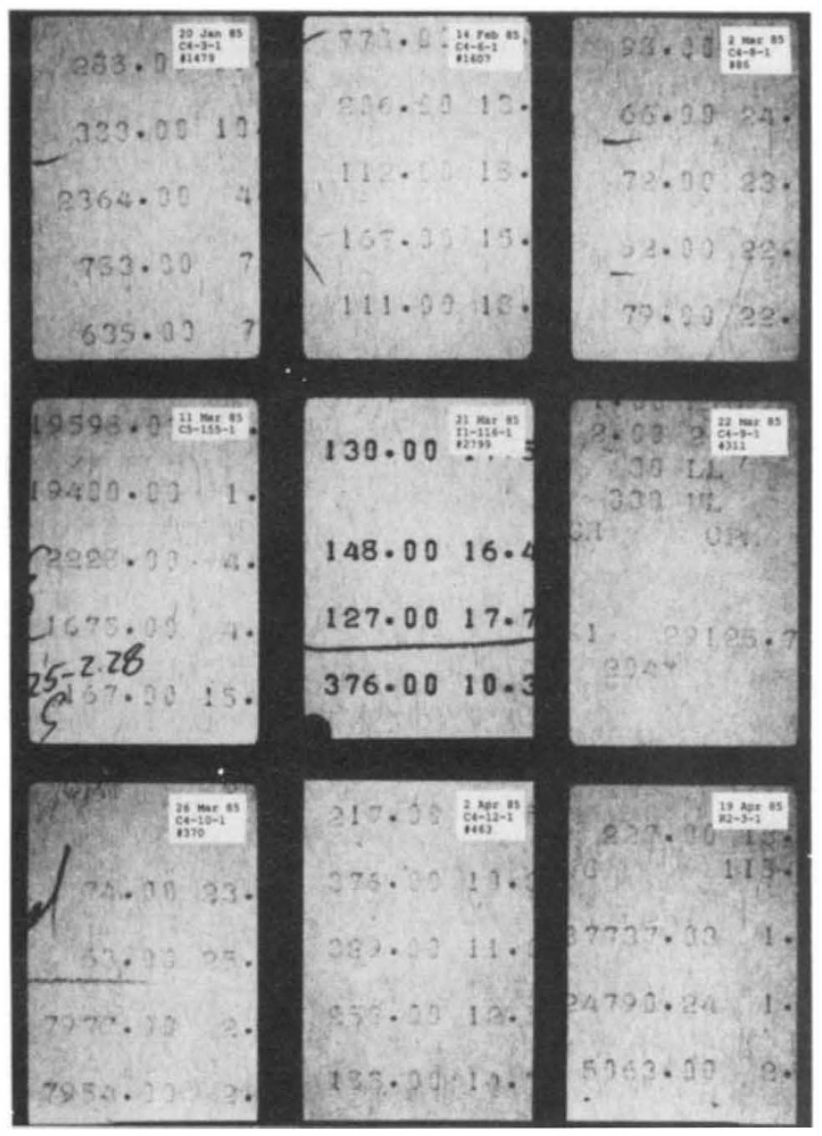
chers and students had kept records of counter tapes from the 1985 period covered by Imanishi-Kari's notebooks. The investigators zoomed in on one of the tapes that came during a key part of Imanishi-Kari's experiments and, most importantly, still displayed its cumulative counter number. Around it they placed tapes from other researchers taken during the same period as the date marked in Imanishi-Kari's notebook.

When the investigators compared the tapes, as in this photograph (made available to Nature by the subcommittee), they immediately noticed the central one Imanishi-Kari's tape - obviously stands out of chronological order. In that tape, the counter clearly had a new ribbon (the tape dated the next day is from a very old ribbon) and the counter number is badly out of sequence. Only one counter accessible to Imanishi-Kari had this characteristic printing style (two zeros after the decimal and so on) and font. Based on this sort of evidence, the Secret Service concluded that the date on the tape is off by many months. Whether that suggests falsification of data is, of course, a completely different matter.

Among the other tools the Secret Service uses in such cases are hand-writing, chemical, microscopic and even neutronactivation analysis to find not only where paper came from, but when and where it was used. They can also determine, for

example, if two apparently concurrent data sets actually came from the same paper roll or notebook.

Christopher Anderson

\section{London}

IN a surprise decision, the Nobel Prize for Medicine has been awarded to Joseph E. Murray, from Brigham and Women's Hospital in Boston, and E. Donnall Thomas, from the Fred Hutchinson Cancer Research Center in Seattle, for their work on human organ and cell transplantation. Murray carried out the first successful kidney transplant between identical twins in 1954 and later pioneered the transplantation of kidneys from deceased donors and the use of whole body irradiation to induce immunosuppression.

In the late $1950 \mathrm{~s}$, Thomas managed to diminish the severe 'graft versus host' reaction in bone marrow transplants and showed that transplanted cells can repopulate the host bone marrow.

\section{Biotechnology no Ionger Wellcome \\ London}

WellCome Biotechnology, since 1982 a separate division within the British pharmaceutical company Wellcome, has become the chief casualty of Wellcome's defeat by the US biotechnology company Genentech over the right to market tissue plasminogen activator (TPA) in the United States (see Nature 344, 692; 1990).

Salvador Moncada, director of research for the Wellcome Foundation, says that the loss of the valuable US market for Wellcome's TPA, together with the cessation of contracts to manufacture animal vaccines in 1992, means that the biotechnology division has lost its economic raison d'etre. It will be wound up over the next few years.

The remaining products from Wellcome Biotechnology (Wellferon, an alpha-interferon, and Campath, an antibody-based anti-cancer agent) and some biotechnology research will be integrated into other sections of the company. Moncada says that the restructuring will involve a reduction in the "head count" of researchers, but he says that the company is is looking for ways to retain as many as possible of the division's 100 or so researchers. Decisions on which research projects are to be retained will be taken in the coming weeks.

The closure of Wellcome Biotechnology is part of a restructuring that includes Wellcome's withdrawal from human vaccine production. News of this has generated considerable criticism, as Wellcome is the single remaining large-scale producer of vaccines in the United Kingdom, and an important supplier for the National Health Service (NHS). But the company says that production will continue until the NHS has found alternative suppliers.

Peter Aldhous

\title{
Transplantation wins again
}

The award is the third in the field of transplantation in the past 30 years, following Sir Peter Medawar and Sir MacFarlane Burnet's 1960 prize for discovering immunological tolerance and the 1980 award to Jean Dausset, George Snell and Baruj Benacerraf for the discovery of HLA human histocompatibility antigens. This year's prize is controversial, as it can be argued that other researchers working at about the same time made equally important contributions to the development of transplantation as a clinical technique, notably two Frenchmen, Jean Hamburger and Georges Matté. Hans Wigzell, chairman of the Nobel Committee, says it is "more difficult in the clinical world [than in basic science] to identify pioneers".

Peter Aldhous 